\title{
Ilusão desfeita: a "aliança especial" Brasil- Estados Unidos e o poder naval brasileiro durante e após a Segunda Guerra Mundial
}

VÁGNER CAMILO ALVES*

Rev. Bras. Polit. Int. 48 (1): $151-177$ [2005]

Introdução

Em ocasiōes diversas Osvaldo Aranha, Ministro das Relações Exteriores de 1938 a 1944, repetiu que a política externa brasileira se resumia na seguinte orientação: apoiar os Estados Unidos em seu papel de potência mundial, em troca do apoio destes a supremacia do Brasil na América do Sul. Conforme a prática na condução da política externa brasileira, essa orientação era descrita por Aranha como uma tradição, legada principalmente pela chancelaria do Barão do Rio Branco. ${ }^{1}$ Inserida no governo Vargas, tal política devia auxiliar os projetos do governo que buscavam centralizar e modernizar o Estado e industrializar o país. Supunha-se, portanto, que uma aliança com os norte-americanos renderia frutos neste sentido.

\footnotetext{
* Pesquisador do Núcleo de Estudos Estratégicos da Universidade Federal Fluminense - UFFNEST e Doutor em Ciência Política pelo Instituto Universitário de Pesquisa do Rio de Janeiro - Iuperj (vgcamilo@bol.com.br).

** McCANN, Frank D.. Aliança Brasil-Estados Unidos, 1937/1945. Rio de Janeiro: Biblioteca do Exército, 1995. p. 243 - 266.

${ }^{1} \mathrm{O}$ período de clara intervenção do Império brasileiro na política do Prata é indicado por Amado Cervo como aquele entre 1851 e 1876. CERVO, Amado Luiz \& BUENO, Clodoaldo, História da Política Exterior do Brasil. Brasília: Editora Universidade de Brasília, 2002. p. 109-128.
} 
Do ponto de vista militar, particularmente durante o Estado Novo (1937-1945), grande esforço foi despendido para a modernização das Forças Armadas. De 1942 a 1945, quando o Brasil esteve em guerra formal contra Alemanha e Itália e em aliança com os Estados Unidos, os auxílios técnico e material fornecidos pelos norte-americanos e a proximidade entre as respectivas forças militares alimentaram a idéia de que os Estados Unidos continuariam subscrevendo uma "aliança especial" com o Brasil, fornecendo os meios para que o país tivesse a supremacia militar no continente. Essa idéia acompanhou os militares brasileiros durante grande parte do pós-guerra, especialmente nos cinco ou seis primeiros anos.

Este artigo destaca essa influência no poder naval brasileiro. Ele é exemplo que confirma não só o comportamento e a política das Forças Armadas nacionais durante o período, mas toda a política externa brasileira de então. Com esse objetivo, desenvolvo meu argumento apresentando os antecedentes da política naval brasileira e as metas de repotencialização deste poder nos anos 30. Posteriormente são analisadas as conseqüências da guerra e da aliança com os Estados Unidos para o poder naval nacional, destacando-se as tentativas, durante e logo após a guerra, de se incrementar esse poder com o auxílio norte-americano. Finalmente, apresento a confusa e negligente política dos Estados Unidos para a América Latina logo após a guerra, e sua resolução no início dos anos 50, derrubando definitivamente qualquer idéia, no âmbito militar e naval, de que haveria por parte dos norte-americanos diretriz para subscrever a supremacia brasileira na América do Sul.

\section{Antecedentes}

O poder naval foi suporte muito importante da política externa do Império brasileiro, particularmente da política para a regiāo do Prata. Durante aproximadamente um quarto de século, o Império teve atuante diplomacia na área, procurando manter sua predominância sobre os vizinhos, impedindo a constituição de uma única entidade política soberana abarcando todo o território do antigo Vice-Reino do Prata. ${ }^{2}$ Ao fim do século XIX, estabilizou-se, na região, o desenho político que

\footnotetext{
2 VIDIGAL, Armando Amorim Ferreira. A Evolução do Pensamento Estratégico Naval Brasileiro. Rio de Janeiro: Biblioteca do Exército, 1985, p. 110.
} 
perdura até os dias de hoje: dois pequenos Estados tampões, o Uruguai e o Paraguai, separando grande parte do território brasileiro do seu grande rival austral, a Argentina, cujo centro político e econômico se situa em Buenos Aires e arredores. A política imperial obteve pleno êxito.

A supremacia da esquadra brasileira durante a maior parte da segunda metade do século XIX foi um fator importante para isso. Tanto na guerra contra Oribe e Rosas (1851-1852), como na longa luta em coalizão contra o Paraguai de Solano López (1864-1870), o predomínio naval brasileiro teve papel destacado para a ulterior vitória do Brasil nos âmbitos militar e diplomático. Para termos uma idéia dessa supremacia regional, basta citar que ao fim da Guerra do Paraguai, a Marinha brasileira não só era a maior do continente, como também, em número de embarcações, era a quinta do mundo, superada apenas pelas esquadras da Inglaterra, Rússia, Estados Unidos e Itália. ${ }^{3}$ Destaca-se que a construção naval militar no país era bastante desenvolvida, fato que dava ao Brasil certa autonomia no setor, algo extremamente positivo para o poder nacional.

O poder naval brasileiro sofreu, a partir de então, visível decréscimo de importância. Politicamente, a Marinha apoiava o regime monárquico. A proclamação da República, com destacada participação de importantes oficiais do Exército, foi um golpe no prestígio interno da instituição. A derrota da Revolta da Armada em 1893, quando a maior parte da força naval brasileira se sublevou contra o presidente e marechal Floriano Peixoto, foi um revés ainda maior, e representa o momento de menor prestígio político da força. O papel da Marinha na política nacional desde aquela data tem sido bem tímido. ${ }^{4}$ Paralelamente, a força naval brasileira sofreu também com o impacto da revolução industrial na tecnologia de construção de navios. Em poucas décadas, todos os aspectos da guerra no mar foram revolucionados, deixando a esquadra brasileira inteiramente obsoleta. A partir desse momento, a construção naval militar passou a ser privilégio de países industrializados, fato que impediu a produção de navios de guerra no país por quase cinqüenta anos.

\footnotetext{
${ }^{3}$ Vide SILVEIRA, Cláudio C. A Marinha e a Política do Exército. in Estudos de História - Franca, vol. 8, n. ${ }^{\circ} 1,2001$.

${ }^{4}$ SCHEINA, Robert L. Latin America, a naval history 1810-1987. Annapolis: Naval Institute Press, 1987, p. 80-87 e 321-322.
} 
Na primeira década do século XX, o avançado estado de obsolescência do poder naval brasileiro e o destacado apoio ao seu reequipamento pelo ministro das Relações Exteriores, o barão do Rio Branco, proporcionaram momentâneo retorno da supremacia naval brasileira na região. A posição de Rio Branco em defesa da repotencialização do poder naval do Brasil foi capital para a materialização dos planos navais de 1904-1906. Rio Branco era, indiscutivelmente, a figura política de maior importância dentro do Estado brasileiro naquele período, tendo-se mantido à frente do Itamaraty durante dez anos (1902-1912) e ao longo de quatro governos distintos. A posse de uma esquadra poderosa não só era parte importante da política de prestígio internacional implementada pelo barão, como também auxiliava sua política de demarcação final de fronteiras.

Uma frota inteira baseada em dois poderosos encouraçados do tipo dreadnought - o Minas Gerais e o São Paulo - e suas respectivas escoltas de cruzadores e contratorpedeiros foi encomendada aos estaleiros britânicos, sendo entregue em 1910. A supremacia naval regional do país foi, desta vez, momentânea. A atitude brasileira provocou uma corrida armamentista no Cone Sul. A Argentina também constituiu sua esquadra de dreadnoughts, feita nos Estados Unidos e entregue em 1914-1915, composta de dois navios ainda mais potentes que os similares brasileiros - o Rivadávia e o Moreno. O Chile, por sua vez, ordenou a construção de dois encouraçados também, tendo ao final adquirido só um deles - o Almirante Latorre, já em $1920 .^{5}$

Além da resposta dos vizinhos hispânicos, outro fator impediria qualquer desejo maior de supremacia pelo Brasil: o atraso industrial. Ele tornou a posse de navios modernos uma miragem de potência, pois a frota adquirida acabou tendo um potencial de utilização bem pequeno. O material humano existente na força marítima brasileira estava aquém

\footnotetext{
${ }^{5}$ Em novembro de 1910, estourou no Rio de Janeiro a "Revolta da Chibata". Durante cinco dias marujos amotinados tomaram parte da esquadra, inclusive os dois poderosos encouraçados recém-chegados ao país. Sob ameaças de bombardeio à capital, os revoltosos pediam o fim dos castigos corporais na Marinha. O evento espelha bem a contradição existente entre os modernos navios comprados e o atraso nas práticas sociais da Marinha nacional. Para uma apreciação mais isenta do evento, recomendo a leitura de dois trabalhos opostos no que concerne ao julgamento dos fatos. MOREL, Edmar, A Revolta da Chibata. Rio de Janeiro: Edições Graal, 1986 e História Naval Brasileira, $5^{\circ}$ volume, tomo I b. Rio de Janeiro: Serviço de Documentação da Marinha, 1997. p. 101-227.
} 
do equipamento adquirido, e a dependência exterior para manutenção e reparos dos navios tornou o poder naval nacional menor do que se esperava. ${ }^{6}$ A esquadra de 1910 , bem pouco tempo após sua chegada, já não podia rivalizar com outras dotadas de navios mais modernos, até mesmo na própria região. Após alguns anos e ela já estava ultrapassada, tendo de ficar grande parte do tempo parada em estaleiros para reforma de algumas importantes unidades. No início dos anos 30, era urgente o reequipamento naval do país, sob risco de o Estado brasileiro ficar privado desse importante elemento do poder nacional.

\section{A política naval brasileira nos anos 30}

Em 1932, um novo plano de dotação naval foi aprovado, já então na presidência provisória de Getúlio Vargas. Apesar da diretriz americanista da política externa brasileira, a crise econômica resultante da recessão mundial tornava os países europeus parceiros comerciais que não podiam ser desprezados. A diplomacia brasileira no período é normalmente caracterizada como de "eqüidistância pragmática", haja vista os fortes vínculos comerciais que o Brasil manteve com o Eixo europeu, sem comprometer, contudo, sua ligação política mais forte com os Estados Unidos. ${ }^{7}$ As trocas comerciais com a Itália e principalmente com a Alemanha cresceram muito na segunda metade da década de 1930, e apresentavam importante vantagem em relação ao comércio realizado com os Estados Unidos: eram feitas na base do escambo, por meio das caixas de compensação, o que poupava as parcas divisas estrangeiras dos países envolvidos. A palavra de ordem da época era "o máximo de relações comerciais e o mínimo de relações políticas com a Europa”, como escreveu o general Góes Monteiro em 1939. ${ }^{8}$

O plano de aquisição naval de 1932, revisto em 34, foi bem realista quanto à capacidade econômica nacional, deixando de lado a idéia de supremacia no Cone Sul e adotando realisticamente, como meta,

\footnotetext{
${ }^{6}$ Vide: MOURA, Gerson. Autonomia na Dependência: A Politica Externa Brasileira de 1935 a 1942. Rio de Janeiro: Nova Fronteira, 1980.

${ }^{7}$ HILTON, Stanley, O Brasil e as Grandes Potências: os aspectos politicos da rivalidade comercial, 1930-1939. Rio de Janeiro: Civilização Brasileira, 1977, p. 71.

${ }^{8}$ VIDIGAL, Armando Amorim Ferreira. Op. cit. p. 76.
} 
o equilíbrio. A frota de combate estabelecida era composta de dois cruzadores de 8.500 toneladas, nove contratorpedeiros de 1.500 toneladas e seis submarinos. ${ }^{9}$ É preciso destacar que naquele momento, a Armada argentina estava bem a frente da brasileira, já tendo iniciado seu processo de modernização, encomendando e recebendo de estaleiros italianos, britânicos e espanhóis dois cruzadores leves, cinco contratorpedeiros e três submarinos. Em 1938-1939, os argentinos incorporariam à sua esquadra mais um moderníssimo cruzador e sete contratorpedeiros construídos na Inglaterra. ${ }^{10}$ Nesse momento, a envelhecida esquadra brasileira mantinhase tão-somente como a terceira do continente. ${ }^{11}$

Créditos foram destinados para o cumprimento do plano, e o país para o qual o governo brasileiro se voltou como provável fornecedor foram os Estados Unidos. Motivos de sobra para isso existiam. Não bastasse a política externa americanista, a Marinha brasileira contava, desde 1922, com uma missão naval daquele país, contratada para inserir o poder naval do Brasil na modernidade, instruindo seus marinheiros em técnicas, táticas e organização modernas. Tentou-se primeiramente a aquisição de cruzadores nos Estados Unidos, mas o clima de guerra e as objeçóes argentinas fizeram o negócio gorar. Oswaldo Aranha, embaixador do Brasil em Washington naqueles tempos, pressionou pelo arrendamento de seis velhos contratorpedeiros em fins de 1936, algo que, a princípio, ficou acertado. Entretanto, os Estados Unidos acabaram cedendo aos protestos da imprensa e da chancelaria argentina, apesar da afirmação de Aranha de que "o alarme de qualquer país diante da atual potência naval do Brasil seria o mesmo que um homem armado de metralhadora temer um outro armado de um simples canivete". ${ }^{12}$ Em face das carências da Marinha, a questão deixou o governo brasileiro desgostoso com os norteamericanos e preocupado com as intençóes do vizinho e rival austral. Imediatamente seis navios daquele tipo foram encomendados a estaleiros britânicos. ${ }^{13}$ A Europa parecia realmente mais profícua como parceiro

\footnotetext{
${ }^{9}$ Marinha Argentina. Tópico Historia - La Armada del S.XX. Disponível em: <http://www.ara.mil.ar>. ${ }^{10}$ VIDIGAL, Armando Amorim Ferreira. Op. cit. p. 78, n. 124.

${ }^{11}$ Apud HILTON, Stanley. Oswaldo Aranha - uma biografia. Rio de Janeiro: Objetiva, 1994. p. 248.

${ }^{12}$ VIDIGAL, Armando Amorim Ferreira. Op. cit. p. 80-81.

${ }^{13}$ HILTON, Stanley. O Brasil e as Grandes Potências: os aspectos politicos da rivalidade comercial 1930-1939. Op. cit. p. 191-192.
} 
neste quesito. Quase na mesma época, também foram adquiridos três submarinos da Itália por intermédio do comércio compensado. ${ }^{14}$

A novidade mais importante do novo plano naval era, no entanto, a ênfase que se deu ao retorno da construção no Brasil. $\mathrm{O}$ antigo arsenal de Marinha não tinha mais condições técnicas para tal empreendimento, mas nos anos 20 um novo e moderno arsenal teve sua construção iniciada ao lado do antigo, na Ilha das Cobras. O novo arsenal foi completado nos anos 30 e, consoante a política de industrialização do governo Vargas, seu ministro da Marinha, vice-almirante Aristides Guilhem, esforçou-se para que grande parte do novo programa naval fosse construído nesse estabelecimento. Em fins de 1935, o arsenal iniciou suas atividades produzindo embarcaçóes simples, mas em 1937, teve início a fabricação de modernos contratorpedeiros classe Marcílio Dias, cujos planos de construção foram cedidos ao Brasil pela Marinha dos Estados Unidos. ${ }^{15}$ Três contratorpedeiros dessa classe foram incorporados à esquadra brasileira em 1943, já durante a guerra, depois de receber o armamento definitivo nos Estados Unidos. A partir de 1940, mais seis contratorpedeiros foram lançados nesse estaleiro, os classe Amazonas. Esses navios foram originalmente aqueles encomendados a construtores britânicos para substituir as unidades que o governo brasileiro não conseguiu arrendar dos Estados Unidos. O início da guerra na Europa, em 1939, fez a Real Marinha requisitar tais unidades. Os brasileiros decidiram, então, com auxílio de técnicos norte-americanos e de equipamento por eles cedidos, produzir também tais embarcações no Brasil. O trabalho foi muito demorado, não só por razões técnicas também em virtude da mudança do cenário internacional no pós-guerra. O primeiro navio classe Amazonas só foi terminado em 1949, e o último somente em $1960 !^{16}$

De toda forma, em menos de cinco anos o novo arsenal de Marinha deu início à produção de nove modernos contratorpedeiros, número inicialmente proposto no plano naval de 1932-1934 para este tipo de embarcação. A moderna construção naval brasileira era obra dos novos

\footnotetext{
${ }^{14}$ VIDIGAL, Armando Amorim Ferreira. Op. cit. p. 81.

15 TELLES, Pedro Carlos da Silva. História da Construção Naval no Brasil. Rio de Janeiro: LAMN, FEMAR, 2001, p. 129.

${ }^{16}$ Ibid p. 128.
} 
governantes, e contou com o prestimoso auxílio técnico norte-americano, principalmente nos anos de guerra. Guilhem, que além de navios, buscou implantar no país também o fabrico de artilharia, torpedos e aviōes, queria mais do que uma simples frota de guerra poderosa. Queria, antes de tudo, retomar certa capacidade autárquica na área, perdida com a revolução tecnológica. Claro que isso estava muito longe de ser alcançado na época da construção destes navios, visto que o índice de nacionalização,

inclusive para a série de contratorpedeiros classe $A$, já na década de 50 (...) - era baixíssimo, quase inexistente: praticamente todos os materiais eram importados, chapas e perfis para casco, máquinas e caldeiras, eixos e hélices, bombas, tubulaçōes e acessórios, materiais e equipamentos elétricos e eletrônicos, etc., etc., e até as tintas para a pintura. A nacionalização dos componentes dos navios só começou com a implantação da grande indústria do governo Juscelino. ${ }^{17}$

Mas o mais importante à época era começar, dar início ao empreendimento, uma vez que, nas palavras de Guilhem,

[...] as usinas que modestamente foram surgindo não se animavam a despender grandes capitais em aparelhamento, cujos produtos não encontravam consumidor e, assim, não se construía por não haver material apropriado, não se produzia material, por não haver produção. Era indispensável desfazer este equilíbrio, e foi o que fez a Administração Naval preparando os seus arsenais e estaleiros para iniciar a construção de navios com material importado, formando, assim, o operariado para, no futuro, quando as indústrias brasileiras produzirem o material, utilizá-lo fazendo obra exclusivamente nacional. ${ }^{18}$

Como em outros setores da industrialização de base, a iniciativa e o investimento pesado por parte do Estado eram condição sine qua non, para o retorno de uma mínima capacidade de construção naval militar brasileira naquele momento.

Não obstante, os modernos navios nas carreiras de construção do Rio de Janeiro, em 1940, a guerra européia já começava a espalhar-se

${ }^{17}$ Apud VIDIGAL, Armando Amorim Ferreira. Op. cit. p. 77.

${ }^{18}$ McCANN, Frank D. Op. cit. p. 185-186 e 191-192. 
pelo Atlântico, e a Marinha brasileira só podia contar com a envelhecida e desfalcada esquadra de 1910 e mais quatro submarinos. Uma vez formalmente na guerra, a aliança militar com os Estados Unidos foi a maior garantia para a continuidade do comércio naval brasileiro, inclusive de cabotagem, em face dos ataques desferidos pelos submarinos do Eixo aos navios mercantes do Brasil. A incapacidade de meios e conhecimento da Marinha de Guerra brasileira para lidar com essa ameaça aparecia a olhos vistos.

\section{A aliança formal Brasil-Estados Unidos e o poder naval brasileiro}

Após o curto período de eqüidistância nas relações exteriores, o início da guerra na Europa obrigou o governo Vargas a alterar a política externa brasileira em direção a um alinhamento mais estreito com os Estado Unidos. O ano de 1940 foi decisivo para Vargas e seu grupo no poder. As pressões norte-americanas para contar com o Brasil no já esperado envolvimento dos Estado Unidos no conflito europeu aumentaram.

A importância do país para os Estados Unidos devia-se, em ordem decrescente: (1) à necessidade de controle de bases no Nordeste brasileiro, vitais para a defesa hemisférica e do Atlântico Sul e, posteriormente, para a própria projeção de poder norte-americana e auxílio, por via aérea, aos aliados lutando na África do Norte, Europa e Extremo Oriente; (2) ao desejo de exclusividade na compra de importantes matérias primas minerais e produtos tropicais brasileiros; e (3) ao grande peso político regional do país, cujo apoio era vital para a consagração da política panamericana dos estadunidenses. Tais atributos faziam do Brasil o mais importante e necessário aliado ibero-americano dos Estados Unidos. Vargas soube barganhar a adesão brasileira ao bloco norte-americano de poder, conseguindo ainda em 1940, o compromisso do governo Roosevelt de auxiliar técnica e financeiramente a construção da siderúrgica de Volta Redonda-RJ. Em janeiro de 1942, o rompimento de relaçōes diplomáticas do Brasil com o Eixo, anunciado pelo chanceler Oswaldo Aranha no Rio de Janeiro, foi recompensado por créditos suplementares para a exploração e a indústria de matérias primas brasileiras, e pela concessão de um fundo de US\$ 200 milhões para as Forças Armadas nacionais adquirirem armas nos Estados Unidos por meio do Lend-Lease. 
A construção de bases aéreas no Nordeste do Brasil pela Pan American já havia sido autorizada verbalmente, pelo presidente Vargas, em princípio de 1941, ainda que o decreto presidencial sobre o assunto só tenha sido publicado em junho daquele ano. $\mathrm{Na}$ verdade, em maio, os norteamericanos iniciaram a travessia de aeronaves pelo Atlântico usando bases brasileiras. ${ }^{19} \mathrm{O}$ alto comando do Exército do Brasil continuou, durante todo esse período, irredutível quanto à presença de tropas norte-americanas em território nacional, mas a Marinha de Guerra dos Estados Unidos já estava autorizada a usar os portos de Recife e Salvador desde o início de 1941. Em fins de abril de 1942, Vargas abriu todos os portos e bases aéreas e navais para as forças do vice-almirante Jonas Ingram, comandante norte-americano do Atlântico Sul. O presidente pôs Ingram também, informalmente, no comando de todas as forças aéreas e navais brasileiras, tornando-o responsável de fato pela defesa marítima nacional. ${ }^{20}$

Uma aliança militar formal entre o Brasil e os Estados Unidos foi então firmada em maio de 1942. Como resultado, duas comissões militares binacionais foram criadas, uma em Washington (Comissão Mista de Defesa Brasil-Estados Unidos, Joint Brazil-United States Defense Commission - JBUSDC) e outra no Rio de Janeiro (Comissão Militar Mista Brasil-Estados Unidos, Joint Brazil-United States Military Commission - JBUSMC). A Comissão de Washington era, de longe, a mais importante, tendo como função o estudo e preparo de recomendações referentes à defesa conjunta dos dois países. A situada no Rio de Janeiro visava auxiliar a implementação das recomendações decididas pela de Washington. ${ }^{21}$ As transferências de equipamentos por meio do Lend-Lease deviam também ser acertadas pela Comissão Mista de Washington.

Em meados de 1942, a guerra atingiu o Brasil do modo mais drástico que o Eixo podia conseguir. Em agosto, em menos de uma semana, seis embarcações comerciais brasileiras foram afundadas no litoral da Bahia e Sergipe, matando centenas de pessoas. A conseqüência direta de tais ataques foi a declaração de guerra do Brasil à Alemanha e à Itália, ainda

\footnotetext{
${ }^{19}$ Ibid. p. 220-222.

20 DAVIS, Sonny B. Brotherhood of Arms: Brazil-United States Military Relations, 1945-1977. University Press of Colorado, 1996, p. 25 - 33

${ }^{21}$ VIDIGAL, Armando Amorim Ferreira. Op. cit. p. 88.
} 
em agosto. A guerra, entretanto, já era realidade para as forças aeronavais brasileiras há alguns meses.

A experiência da guerra anti-submarina marcará profundamente a Marinha brasileira. Como já comentado, os vasos de guerra disponíveis no início da década de 1940, eram, em sua maioria, obsoletos e de nenhuma serventia contra submarinos. A doutrina e as táticas ensinadas também não previam tal tipo de guerra. Como resultado, existia completa incapacidade da força naval nacional de lidar com tal ameaça. A solução parecia ser justamente a aliança com os Estados Unidos, formalização daquilo que alguns decisores do passado viam como meta maior da política externa nacional.

Durante a guerra, em termos navais, a proteção da navegação na costa brasileira coube primordialmente às forças norte-americanas, atuando a Marinha do Brasil subsidiariamente. Mesmo o papel coadjuvante só foi possível graças à incorporação de algumas embarcaçōes modernas em construção no arsenal de Marinha e, especialmente, em virtude da transferência de navios norte-americanos especializados nesse tipo de combate através do Lend-Lease. Um total de 24 embarcações foram cedidas pelos Estados Unidos ao Brasil, de fins de 1942 até princípios de 1945. Desse total, 16 eram pequenos navios do tipo caça-submarino, adequados primordialmente para o combate aos $U$-boats em águas costeiras, além de oito contratorpedeiros de escolta classe Bertioga, dotados de radar e sonar. Estes, para além de sua capacidade anti-submarina, constituíram acréscimo destacado ao poder da esquadra nacional regionalmente. ${ }^{22}$ Ao final da guerra, a Marinha brasileira era a única do continente com grande experiência de combate anti-submarino, e a esquadra nacional, com 11 unidades modernas, mais seis em construção no arsenal da Ilha das Cobras, parecia, pelo menos, poder equiparar-se com a do histórico rival austral.

O equilíbrio, entretanto, não era mais o objetivo. A aliança com os Estados Unidos podia e devia fazer mais. A Comissão Mista de Washington, composta de duas delegações nacionais, que, por seu turno, eram formadas por um representante de cada força, tinha em Álvaro Rodrigues Vasconcelos o representante da Marinha brasileira. Os créditos

${ }^{22}$ Arquivo Getúlio Vargas rolo 7, microfilmes 297 e 298 - a partir de agora AGV 7, 297 e 298. 
por meio do Lend-Lease e a aliança com os Estados Unidos eram pensados como instrumentos perfeitos para, além das contingências específicas da guerra, incrementar o poder naval nacional de modo a tornar o Brasil predominante nesse setor no pós-guerra em termos continentais.

Em correspondência entre Vasconcelos e o presidente Vargas, em junho e julho de 1943, o almirante recomendava ao presidente acréscimo de 100 a 200 milhões de dólares no limite original de US\$ 200 milhões, para aquisição de armas nos Estados Unidos pelo Lend-Lease. Vasconcelos declarava que a quantia destinada à Marinha, US\$ 50 milhões, não se mostrava suficiente e que somente as requisições do Exército e da Força Aérea atingiam o limite de US\$200 milhôes. Vargas acenou positivamente, respondendo que havia recomendado ao Ministro das Relaçóes Exteriores "as necessárias providências para elevarmos, no mínimo, para 300 milhōes [o crédito]". O presidente aproveitou também para recomendar ao almirante a aquisição de grandes navios nos Estados Unidos, algo como "meia dúzia de cruzadores de sete a dez mil toneladas e dez destroyers semelhantes aos Marcílios" para que nossa Marinha pudesse operar e "colaborar no esforço de guerra mesmo longe de nossas costas". ${ }^{23}$

O clima em Washington não parecia, a princípio, avesso a tais metas. Em novembro de 1943, Vasconcelos escreveu novamente ao presidente e informou que o chefe da Divisão pan-americana da Marinha dos Estados Unidos dera ciência de que era tempo de o governo brasileiro, pelos canais competentes, "manifestar que material flutuante desejaria receber dos Estados Unidos quando, vitoriosos os aliados, tivesse o governo norteamericano de desfazer-se de muitos navios de sua esquadra”.

Segundo Vasconcelos, o representante do Navy Department para as Américas salientara que todos os países da América do Sul "desejariam receber alguns ou muitos navios", mas que o Brasil,

pela posição que assumira, por sua extensão e população, por seu desenvolvimento econômico e por sua situação geográfica, deveria ser a mais bem armada dessas repúblicas e o armamento naval de qualquer das outras repúblicas deveria ficar sendo função daquele que fosse permitido ao Brasil possuir. ${ }^{24}$

${ }^{23}$ AGV 8, 6.

${ }^{24}$ AGV 8, 3. 
Vargas tomou então as providências ao seu alcance, e recomendou ao embaixador do Brasil nos Estados Unidos, em janeiro de 1944, tratar imediatamente a questão. ${ }^{25} \mathrm{Em}$ abril, o presidente foi além. Escreveu diretamente a Roosevelt sobre o assunto em um lance de puro oportunismo político.

O primeiro semestre de 1944 é o momento de maior pressão norte-americana sobre a Argentina, cujo governo Farrel/ Perón era tido em Washington como a "ovelha negra" da "comunidade pan-americana de naçóes”. Os Estados Unidos não reconheciam tal governo, que derrubara o do presidente Ramirez depois que este, pressionado pelos Estados Unidos, rompera as relações diplomáticas com a Alemanha e o Japão. A política de Roosevelt e de seu secretário de Estado, Cordell Hull, além de boicotes à Argentina, buscou contrabalançar a suposta influência do país na região incrementando o poder militar brasileiro. É nesse quadro que podemos compreender os pedidos de Vargas ao presidente norte-americano. Getulio recorda na carta o episódio da não transferência dos velhos contratorpedeiros norte-americanos em 1937, devido às reclamações argentinas, frisando que a ausência de tais navios na esquadra brasileira em muito atrapalhara a cooperação Brasil-Estados Unidos nas ações anti-submarinas da presente guerra.

Com base em documento produzido pelo Estado Maior da Armada, Vargas pedia a cessão, mediante Lend-Lease ou pela forma mais conveniente, de um substancial número de embarcações, entre as quais destacavam-se dois cruzadores pesados e dois cruzadores leves, dois porta-aviōes, três contratorpedeiros condutores de flotilha e 12 unidades menores do tipo de 1.500 toneladas. ${ }^{26}$ Não devemos esquecer que a essas unidades temos de adicionar as produzidas ou em produção no arsenal de Marinha do Rio de Janeiro. No documento preparado pelo Estado Maior da Armada, tal frota era considerada como suficiente à "defesa de nossa extensa costa marítima e à manutenção da hegemonia do Brasil no Atlântico Sul, com o propósito de salvaguardar, em cooperação com as nações aliadas, a paz no continente sul-americano". Vargas, por seu turno, reiterava ao presidente norte-americano que os navios cedidos serviriam

\footnotetext{
25 AGV 8, 12 a 14.

${ }^{26}$ AGV 8, 211 e 12 a 14.
} 
para aumentar a "segurança do continente americano, porque a prova da nossa cooperação leal e franca já está feita”, salientando também que em "novas emergências seguiremos nossa tradição de política exterior ao lado da Nação Americana, e prontos a colaborar na defesa do continente e a garantir a paz entre as nações latino-americanas". ${ }^{27}$

A resposta de Roosevelt foi polidamente negativa. A Marinha norte-americana não podia transferir tais navios naquele momento aos brasileiros, já que necessitava deles nos decisivos combates que se realizavam contra os japoneses no Pacífico. Só o que podia ser transferido, então, eram os primeiros quatro contratorpedeiros classe Bertioga. Roosevelt esclarecia ao final de sua resposta, no entanto, que conversaçóes entre os respectivos staffs militares dos dois países deveriam ter início, de modo que o poder militar total do país fosse determinado "tendo como princípio básico à defesa hemisférica" ${ }^{28}$

As negociações entre os staffs ocorreram já no segundo semestre de 1944. Para Vargas, a aliança em tempo de guerra deveria prolongar-se no futuro, e as negociações que então se iniciavam visariam a tal desiderato. Nas suas palavras, o que seria discutido era “(...) uma verdadeira aliança militar permanente, pois vamos cuidar dos problemas de armamento no após-guerra, para assegurar a paz”. As ameaças a serem contidas poderiam vir de fora ou de dentro do continente. Vargas enumerava muitos indícios para comprovar a possível ameaça que a Argentina representava naquele momento. Para lidar com isso, os norte-americanos deveriam "preparar militarmente o Brasil para que este, na América do Sul, possa não só defender-se, como também os interesses da própria América do Sul e os dos outros países sul-americanos, se agredidos". ${ }^{29}$ $\mathrm{O}$ resultado das discussóes conjuntas, especificamente quanto ao poder naval brasileiro, foi um aumento projetado ainda maior vis-à-vis o proposto no documento do Estado Maior da Armada, que Vargas apresentara a

${ }^{27}$ Foreign Relations of the United States - Diplomatic Papers (FRUS), 1944, volume VII, The American Republics. Washington: Department of State, Government Printing Office, 1967. p. 583-584 e AGV 8, 14 e 15.

${ }^{28}$ Grifos no original. AGV 8, 461 a 465.

${ }^{29}$ Além das unidades pedidas, programava-se a transferência de mais dois encouraçados classe Nevada e de nove submarinos, além de uma série de outros navios auxiliares. Foreign Relations of the United States - Diplomatic Papers (FRUS), 1945, Volume IX, The American Republics. Washington: Department of State, Government Printing Office, 1969, p. 602. 
Roosevelt em abril. ${ }^{30}$ A predominância naval do Brasil na América do Sul parecia ser não só desejada pelas autoridades nacionais, mas também pelo presidente Roosevelt e o Navy Department. Não admira que a idéia de aliança especial ligando Brasil e Estados Unidos fosse um consenso entre os atores políticos mais importantes do governo brasileiro.

\section{O abandono norte-americano no pós-guerra}

A negligência da política externa norte-americana para a América Ibérica durante o pós-guerra é notável, principalmente levando-se em conta que a região havia sido prioridade para o país nos anos 30, com a política de "boa vizinhança" e o ideal pan-americanista defendido pelo governo Roosevelt. O motivo do descaso foi, primordialmente, o início da Guerra Fria logo após o fim do segundo conflito mundial. Envolvidos na tarefa de conter o comunismo internacional, ou mais precisamente, a URSS e seus aliados, os Estados Unidos passaram a privilegiar, nas relações exteriores, os países da Europa e Ásia situados no entorno do território soviético. $\mathrm{O}$ resultado disso foi que econômica e militarmente a América Latina não teve auxílio de monta na segunda metade dos anos 40 e, em menor grau, nos anos 50, ao contrário do que ocorreu com muitos países eurasianos no mesmo período. A América Latina só voltou a preocupar os norte-americanos mais fortemente nos anos 60 , após Cuba ter-se tornado satélite soviético no Caribe, resultado de uma revolução popular e autóctone.

Imediatamente após o fim da Segunda Guerra Mundial, no entanto, o descaso dos Estados Unidos deu-se mais por confusão do que por desígnio político. Roosevelt morreu ainda durante a guerra e seu sucessor, Harry Truman, não tinha nem conhecimento nem força política para imprimir imediatamente marca própria à política externa norte-americana. Pairou então muita dúvida sobre a validade dos compromissos norte-americanos dos tempos de guerra. No Brasil, João Neves da Fontoura, o novo ministro das Relações Exteriores do governo Dutra, afirmou em janeiro de 1946, quando recebia o prefeito de Nova Iorque no Rio de Janeiro, que o Brasil continuava apoiando a política

${ }^{30}$ Apud DAVIS, Sonny B. Op. cit. p. 54. 
norte-americana no mundo, ainda que ajudasse muito "saber qual [era] essa política" ${ }^{31}$

Especificamente em relação ao acordo para a transferência de equipamentos bélicos, firmado por Vargas na segunda metade de 1944, surgiram dúvidas sobre a seriedade dos norte-americanos em cumprir o negociado. Acordos semelhantes haviam sido firmados com a maior parte dos países na região, ainda que o Brasil fosse certamente o mais aquinhoado deles. Na ausência de uma orientação presidencial sobre o assunto, a questão dependia, para a implementação, da vontade das organizações estatais norte-americanas, que tinham poder decisório para isso. A posição delas, entretanto, era divergente.

Os militares, em geral, queriam cumprir o acordado. Suas razões eram basicamente duas: agradar seus pares latino-americanos, atores políticos de importância em seus respectivos países; e padronizar o equipamento militar em toda a região, de modo a garantir mercado e influência para os Estados Unidos, dificultando qualquer infiltração européia no continente. Em 1946, o perigo, para os militares estadunidenses, era menos o comunismo do que o retorno da influência militar britânica na área. ${ }^{32}$ O Departamento de Estado, entretanto, não via as coisas da mesma maneira. Os diplomatas norte-americanos enfatizavam os possíveis custos que a transferência de armas poderia ter no continente. Em termos econômicos, a simples manutenção de grandes forças militares podia comprometer seriamente as finanças dos países receptores, o que certamente afetaria as relações dos Estados Unidos na região. Além disso, havia também a preocupação sobre o uso que os militares latino-americanos podiam fazer do equipamento. Agressóes contra países vizinhos e golpes militares eram possibilidades que desencorajavam o cumprimento do acordo. Em face a essa divisão, não se cumpriu as tratativas dos tempos de guerra. Em última instância, o Departamento de Estado acabou exercendo um poder de veto sobre a questão naquele momento.

Adolf Berle Jr., embaixador dos Estados Unidos no Brasil, levantava dúvidas sobre a propriedade de se entregar ao Brasil substancial volume

\footnotetext{
${ }^{31}$ PACH, Chester J. Jr. The Containment of U.S. Military Aid to Latin America, 1944-49. In: Diplomatic History, vol. 6, n. ${ }^{\circ}$ 3, 1982, p. 234.

32 Foreign Relations of the United States - Diplomatic Papers (FRUS), 1945, volume IX, The American Republics. Op. cit. p. 604.
} 
de equipamento bélico já em julho de 1945. Especificamente quanto ao aspecto naval, Berle duvidava da capacidade de os brasileiros operarem com eficiência algumas belonaves, tão modernas e complexas eram. Para ele, o objetivo dos militares brasileiros era tão-somente aumentar seu poder e prestígio político, interna e externamente. Berle não era favorável à cessão de equipamento, ainda que se mostrasse inclinado a apoiar o auxílio especificamente ligado a projetos para melhoria da infra-estrutura militar brasileira, como construção de novas bases navais, aparelhamento de aeroportos, incremento da malha de transportes nacional, tanto rodoviária como ferroviária, etc. Com relação às bases navais, a opinião do embaixador era que,

Essas bases seriam de ótimo uso no caso de operações de qualquer tipo, seja para manter a paz dentro do hemisfério, seja para defender o hemisfério de ataques de fora; mas seu uso principal seria provavelmente apoiar as operaçōes da Marinha dos Estados Unidos. ${ }^{33}$

A partir de meados de 1947, com a adoção da Doutrina Truman, a política externa dos Estados Unidos passa a ter um objetivo claro, que marcaria os próximos quarenta anos das suas relaçōes exteriores. Truman comprometeu-se a auxiliar econômica e militarmente Grécia e Turquia, atestando que os Estados Unidos, como líder do "mundo livre", conteria o comunismo, onde quer que ele buscasse expandir-se. Nesse mesmo ano foi assinado, no âmbito das Américas, o Tratado Interamericano de Assistência Recíproca (Tiar) durante a Conferência do Rio de Janeiro, que tacitamente considerava a União Soviética como adversário de todo o hemisfério. Em 1948, foi constituída a Organização dos Estados Americanos (OEA), que institucionalizou o pan-americanismo. Ambas organizaçóes visavam formalizar a liderança norte-americana de facto sobre as Américas.

\footnotetext{
33 PACH, Chester J. Jr. Op. cit. p. 242. O secretário de Estado Dean Acheson frisava a todas as embaixadas norte-americanas na América Latina, inclusive, que os governos da região deviam ser convencidos de que não era necessário a compra de mais armas, e que a simples existência do TIAR era suficiente para assegurar os países da área. Foreign Relations of the United States Diplomatic Papers (FRUS), 1950, volume I, National Security Affairs; Foreign Economic Policy. Washington: Department of State, Government Printing Office, 197, p. 620 - 622.
} 
Ao mesmo tempo, a questão da assistência militar para a região voltou à tona. Ela era apresentada agora como medida de contenção ao comunismo soviético. Os entraves postos pela diplomacia estadunidense foram retirados. Era preciso, acima de tudo, armar a regiāo e padronizar o equipamento. A implementação do acordo negociado por brasileiros e norte-americanos, inclusive a cessão/venda facilitada de uma enorme esquadra de guerra, voltava a ser possível.

Nesse momento, entretanto, ainda que existisse consenso entre militares e diplomatas norte-americanos sobre a necessidade de armar os latino-americanos, demandas mais prementes alhures deixavam a região em posição muito baixa na lista de prioridades dos Estados Unidos. As áreas ao alcance do poder militar soviético, Europa, Oriente Médio e Extremo Oriente estavam no topo da lista. Ademais, em face do grande número de clientes, o enorme surplus de guerra norte-americano já não parecia suficiente. Em 1948, as reservas de determinados tipos de armamento já se aproximavam do fim, enquanto outros, a despeito do grande estoque, não eram mais úteis por estarem tecnologicamente ultrapassados. Ainda que especificamente em relação aos navios não se aplicasse nem uma coisa nem outra, a alocação de recursos militares para os latino-americanos precisava ser decidida como um todo, pois necessitava ser aprovada pelo Congresso dos Estados Unidos.

A legislação específica para auxílio militar à região, o InterAmerican Military Cooperation Act, não foi adiante em virtude das novas responsabilidades assumidas pelos norte-americanos alhures. Os programas interinos que possibilitavam a transferência de algum equipamento militar para a região terminaram definitivamente em 1948. Quando o Congresso dos Estados Unidos finalmente passou o primeiro grande programa de ajuda militar em 1949, lastreando a política de contenção adotada pelo Executivo, nem um único centavo foi destinado para a América Latina. Embora fosse prevista a doação de quase 1 bilhão e meio de dólares em armas para os mais diversos países, os latino-americanos só podiam comprar armas norte-americanas a preços comerciais. ${ }^{34}$

Políticos e militares brasileiros envolvidos com a questão naval estavam, é claro, decepcionados. De 1945 a 1950, as transferências de equipamento para a Armada brasileira resumiram-se a peças de reposição e navios de apoio, o que não alterou o status da força vis-à-vis as demais 
esquadras regionais. Se existia amargura pela falta de reconhecimento dos serviços prestados pelo país durante a última guerra mundial, existia também esperança de que, quando os Estados Unidos cedessem navios aos países da região, o Brasil teria tratamento preferencial. No início de 1947, o ministro Silvio de Noronha, esperançoso, escrevia em seu relatório para o Presidente que a constituição de uma "força-tarefa equilibrada”, dotada de cruzadores, porta-aviōes, contratorpedeiros e submarinos, dependia do auxílio norte-americano. Em seu relatório seguinte, entretanto, entregue no início de 1951, ao término do governo Dutra, as esperanças de concretização de tal auxílio eram muito menores e o ministério pedia celeridade na aprovação pelo Congresso brasileiro de um fundo naval permanente para renovação da Esquadra nacional sem ajuda estrangeira. ${ }^{35}$

A despeito disso, a Marinha brasileira aceitava sua subordinação à estratégia naval norte-americana, o que explica a pouca importância dada pela força, após a Segunda Guerra Mundial, a outros usos do poder naval que não o anti-submarino. Isso era reflexo da visão norteamericana sobre o papel da esquadra brasileira como força auxiliar contra submarinos russos no Atlântico Sul, na hipótese de a Guerra Fria esquentar. Era compreensível, ainda que pouco aceitável, na visão dos decisores brasileiros, a primazia de países de outras regiōes na distribuição de equipamento bélico pelos Estados Unidos, tendo em vista o perigo muito maior que eles corriam em face de uma agressão comunista. Inadmissível para eles, entretanto, era que o Brasil pudesse vir a ser tratado pelos norte-americanos de maneira semelhante aos demais países hispano-americanos, especialmente a Argentina.

\section{A venda dos Cruzadores}

Em 1950, o estado dos navios-capitais da esquadra brasileira era grave. Os encouraçados dreadnought Minas Gerais e São Paulo, os mais poderosos do mundo quando lançados ao mar em 1910, não passavam de sucatas flutuantes. A despeito da tônica anti-submarina que os Estados

\footnotetext{
${ }^{34}$ Relatórios Ministeriais de 1946, p. 4-5, e de 1946-1950, p. 5-8.

${ }^{35}$ Marinha Argentina. Tópico Historia - La Armada del S.XX. Disponível em: <http://www.ara.mil.ar>.
} 
Unidos impunham não só a Marinha brasileira, mas a todas as marinhas da região, a posse de algumas belonaves de maior peso era frisada pela força brasileira até por razões de prestígio. Convém lembrar também que a Argentina, apesar da igual obsolescência de seus encouraçados do início do século, exibia em seu inventário naval três cruzadores leves, construídos nos anos 30, tipo de embarcação em falta na esquadra brasileira. A belonave construída na Inglaterra tinha até radar, fruto de modernização realizada em Londres em $1946 .{ }^{36}$

Após insistentes pedidos, o governo norte-americano, por meio de emenda ao programa de auxílio militar aprovado pelo Congresso, conseguiu tornar disponível ao Brasil, a preços irrisórios, dois cruzadores leves classe Brooklyn, navios com 10.000 toneladas de deslocamento, canhões principais de 6 polegadas, radar e forte bateria antiaérea. $O$ ministro Silvio de Noronha caracterizou tal compra como o acontecimento mais notável, no tocante à aquisição de navios, desde a incorporação das naus do programa de $1904-1906 .{ }^{37}$ Esses vasos de guerra, se não tornava o poder naval brasileiro preponderante regionalmente, pelo menos daria a ele leve vantagem sobre o de seu vizinho austral, o que, pelo menos, mantinha a aparência da "aliança especial" para políticos e militares brasileiros.

A transferência dos cruzadores, entretanto, em vez de salvar a idéia da aliança foi, na verdade, seu epitáfio. Os Estados Unidos, simultaneamente às negociações com o governo brasileiro, achou por bem oferecer navios, do mesmíssimo tipo e em iguais condições de compra, também para o Chile e a Argentina. ${ }^{38}$ Em 1951, não só a esquadra brasileira foi acrescida de dois potentes e modernos cruzadores - o Barroso e o Tamandaré- como o

\footnotetext{
${ }^{36}$ Relatório Ministerial de 1946-1950, p. 123-124.

37 Foreign Relations of the United States - Diplomatic Papers (FRUS), 1950, Volume I, National Security Affairs; Foreign Economic Policy. Op. cit. p. 653.

${ }^{38}$ Enquanto o Brasil rompeu relações diplomáticas com o Eixo em janeiro de 1942 e declarou guerra em agosto do mesmo ano, Chile e, principalmente, Argentina, mantiveram suas posições de neutralidade na guerra durante muito mais tempo. O Chile rompeu relações com o Eixo um ano após o Brasil e a Argentina somente o fez em fevereiro de 1944. A declaração de guerra dos dois países só ocorreu em 1945, em virtude de exigência dos Estados Unidos como condição para participar da Conferência de São Francisco, quando a Organização das Nações Unidas foi constituída. Ainda assim, os argentinos acabaram declarando guerra após o prazo estabelecido, em 29 de abril, recebendo no dia seguinte o convite para participar da Conferência que já havia iniciado. HUMPHREYS, R. A. Latin America and the Second World War, Volume Two 1942-1945. London: Athlone, 1982. Passim.
} 
mesmo ocorreu com as esquadras chilena e argentina - com o O'Higgins e o Capitán Prat, e o General Belgrano e o 9 de Julio, respectivamente. À semelhança do equilíbrio atingido nos anos 10, entre as esquadras de encouraçados dos países do Cone Sul, nos anos 50 o mesmo ocorria, só que dessa vez por decisão única do país mais poderoso do mundo.

A política norte-americana para a América Latina, quanto ao poder naval, além da total subordinação, adotava também o princípio do equilíbrio, especialmente entre os países do Cone Sul. Diferente do esperado pelos decisores brasileiros, o histórico diferenciado de participação na Segunda Guerra Mundial nada influiu nas decisões norteamericanas naquele momento. ${ }^{39}$ Tampouco afetou, especificamente sobre o auxílio à Argentina, o fato de Perón ser o único líder no hemisfério que desenvolvia política externa relativamente não-alinhada, defensora de uma "terceira posição" no sistema internacional. O equilíbrio naval entre Argentina, Brasil e Chile (ABC), orientação expressa pelos Estados Unidos na venda dos cruzadores, manter-se-ia nas décadas seguintes nas demais transferências de embarcação efetuadas.

Tentativas de mudar essa orientação foram feitas por autoridades políticas nacionais ainda no início dos anos 50. João Neves da Fontoura, então ministro das Relações Exteriores no segundo governo Vargas, aproveitou a IV Conferência de Chanceleres americanos, em abril de 1951, convocada pelos norte-americanos em conseqüência da crise internacional causada pela intervenção chinesa na Guerra da Coréia, para tentar barganhar com os Estados Unidos. Entre as demandas brasileiras, constava um auxílio militar diferenciado ao Brasil com relação aos demais países latino-americanos. Segundo João Neves, o Brasil esperava receber armamento para suas três forças,

[...] em base semelhante às aplicadas às Nações signatárias do Pacto do Atlântico Norte. [...) Mas o Brasil não pode ]admitir que, no tocante à distribuição de armamentos, seja ele feito com o mesmo critério de igualdade em relação a outras nações, como aconteceu no caso dos cruzadores. Reclamamos o princípio de fornecimentos em proporção às tarefas de defesa comum aceitas por cada país. Nessas condições, não

${ }^{39}$ AGV 12, 619 e 620. 
poderemos receber quantidades de armamentos e suprimentos militares iguais aos dos que, por ventura, sejam dados às Repúblicas americanas, dado a linha de conduta semi-neutralista pelas mesmas adotada, em face da atual emergência. ${ }^{40}$

Em 1952, o governo brasileiro assinou acordo militar com os Estados Unidos e, no ano seguinte, ele foi aprovado pelo Congresso e entrou em vigor. $\mathrm{O}$ Brasil passou a fazer jus ao auxílio que os Estados Unidos distribuíam por meio de seu programa de ajuda militar anual, que a partir de 1951 passou a contar com pequena verba destinada especificamente à América Latina, algo inicialmente inexistente. No que se refere ao poder naval, no entanto, nada mudou. A política de equilíbrio entre $\mathrm{ABC}$ prosseguiu no restante dos anos 50 e também nos anos 60 .

À primeira vista, em termos práticos, o fim da ilusão sobre a "aliança especial” com os Estados Unidos não alterou a política naval brasileira. A Marinha continuou recebendo os meios flutuantes que os norte-americanos se dispunham a transferir, ainda que esses equilibrassem tais ações com transferências quase simultâneas para as demais armadas do Cone Sul. Os custos inviabilizavam qualquer distanciamento dos Estados Unidos. Em 1952, todo o fundo naval aprovado pelo Congresso, se fosse gasto na compra de navios a preços de mercado, seria suficiente para a aquisição de um único contratorpedeiro de esquadra moderno. ${ }^{41} \mathrm{~A}$ influência doutrinária e tática continuou existindo, espelho da subordinação que o poder naval brasileiro tinha à estratégia marítima norte-americana durante a Guerra Fria. Em termos retóricos, os comandantes podiam lamentar o abandono do aliado dos tempos de guerra, mas pouco podia ser feito para alterar a posição do Brasil nesse aspecto.

O pouco, entretanto, foi feito. Já na primeira metade dos anos 50 , o Brasil voltou a adquirir navios de outros fornecedores do "mundo livre". Renato Guillobel, ministro da Marinha no segundo governo Vargas, optou por gastar os parcos recursos da força em navios auxiliares - rebocadores de alto-mar, navios-hidrográficos e transportes - de modo a fortalecer a logística da armada. As compras foram feitas na Holanda e no Japão, "que aceitavam o pagamento em cruzeiros, a longo

40 GUILLOBEL, Renato de Almeida. Memórias. Rio de Janeiro: Fundação IBGE, 1973. p. 272.

${ }^{41}$ Ibid p. 303. 
prazo e sujeito, se assim coubesse, à troca por matérias-primas de nossa conveniência”. ${ }^{42}$ Mais adiante, quando havia mais recursos, durante o governo de Juscelino Kubitschek, o Brasil voltou a adquirir na Europa naus de combate. Foi comprado um porta-aviōes leve inglês que, a despeito de ter como função quase exclusiva a guerra anti-submarina, simbolizava um tênue afastamento da dependência norte-americana, regra nas últimas duas décadas. ${ }^{43}$

\section{Conclusão}

A preponderância naval brasileira na América do Sul foi um sonho acalentado por militares e políticos brasileiros nos anos finais da Segunda Guerra Mundial, que contou momentaneamente com o incentivo de importantes atores do governo e das forças armadas norte-americanas. Esse projeto era parte da confiança mais geral de que a guerra tinha finalmente forjado a tantas vezes propalada "aliança especial" BrasilEstados Unidos, e que o corolário dessa aliança seria o aporte, pelos norte-americanos, de todo auxílio possível, financeiro, tecnológico e militar, para garantir a hegemonia do Brasil na América do Sul. O Brasil agiria então como uma espécie de procurador dos norte-americanos na região, mantendo e defendendo o status quo.

$\mathrm{Na}$ segunda metade dos anos 40, os projetos de predomínio naval do Brasil não se concretizaram por exclusiva falta dos norte-americanos. As razões práticas que sedimentaram a aliança desapareceram com a derrota do Eixo e o surgimento da Guerra Fria. A decepção dos decisores nacionais foi contrabalançada, em parte, pela crença contínua de que o Brasil era diferente das demais repúblicas latino-americanas e assim seria tratado, pelos Estados Unidos, em momento oportuno. A venda dos cruzadores para os países do Cone Sul, em 1951, pautada pela idéia do equilíbrio de poder na região, acabou com qualquer ilusão de que a relação Brasil-Estados Unidos fosse de alguma maneira especial.

\footnotetext{
42 Não estava nos planos do governo norte-americano, nesse momento, a operação de tal tipo de navio pelo Brasil ou qualquer país sul-americano. História Naval Brasileira, $5^{\circ}$ volume, tomo II. Rio de Janeiro: Serviço de Documentação Geral da Marinha, 1985. p. 444.

${ }^{43}$ CAMINHA, Herick Marques. História Administrativa do Brasil-Organização e Administração do Ministério da Marinha na República. Brasília: FUNCEP, 1989, p. 288-289.
} 
Em 1953, a esquadra brasileira era composta de dois cruzadores leves, 15 contratorpedeiros - quatro navios classe Amazonas haviam sido incorporados - e três submarinos. ${ }^{44}$ Tal frota era muito semelhante à prevista no plano de aquisição naval de 1932-1934, em que se buscava, consoante a capacidade econômica nacional, certa paridade com os vizinhos do Cone Sul. Comparada às previsões de meados dos anos 40, entretanto, a esquadra nacional era apenas uma sombra.

A subordinação material, tática e doutrinária da Marinha brasileira nos anos 50 e 60 em nada alterou a decisão norte-americana de manter o equilíbrio naval entre $\mathrm{ABC}$. O fim da demanda de guerra, o elevado preço de navios modernos e a oferta gratuita ou quase gratuita deles pelos Estados Unidos a partir dos anos 50, interrompeu o programa de construção naval militar brasileiro do fim dos anos 30, que havia contado até com auxílio norte-americano. Quase trinta anos se passaram até que um grande navio de guerra fosse novamente lançado no arsenal de marinha, em meados dos anos 70 .

A dependência teve também conseqüência prejudicial para o pensamento estratégico da força naval brasileira, que se acostumou a pensar em termos de ações em conjunto com a marinha dos Estados Unidos, algo corporificado na ênfase anti-submarina como principal papel da Marinha brasileira, à custa de outras modalidades de guerra naval.

A conscientização do fracasso da "aliança especial”, entretanto, fez também os decisores brasileiros voltarem a pensar, a curto prazo, em outros fornecedores de navios no bloco ocidental, de modo que se pudesse fugir um pouco da subordinação aos Estados Unidos e de sua política de estrito equilíbrio no Cone Sul. A longo prazo, sonhava-se com tempos em que, fruto do desenvolvimento econômico e industrial do país, a Marinha pudesse constituir poder naval por meio de produção própria novamente. Dessa vez, para apoiar política externa autônoma e independente. Isso não era possível nos anos 50, mas a crença na "aliança especial", forte na década anterior, havia em grande medida desaparecido.

Recebido em 27 de março de 2005 Aprovado em 15 de maio de 2005

${ }^{44}$ TELLES, Pedro Carlos da Silva. Op. cit. p. 197. 


\section{Referências Bibliográficas}

ARQUIVO GETULIO VARGAS (AGV), Centro de Pesquisa e Documentação de História Contemporânea do Brasil - CPDOC/FGV, Rio de Janeiro.

CAMINHA, Herick Marques. História Administrativa do Brasil-Organização e Administração do Ministério da Marinha na República. Brasília: FUNCEP, 1989.

CERVO, Amado Luiz \& BUENO, Clodoaldo. História da Política Exterior do Brasil. Brasília: Editora Universidade de Brasília, 2002.

DAVIS, Sonny B.. Brotherhood of Arms: Brazil-United States Military Relations, 1945-1977. University Press of Colorado, 1996.

DEPARTAMENT OF STATE.

Foreign Relations of the United States - Diplomatic Papers (FRUS), 1944, volume VII, The American Republics. Washington: Government Printing Office, 1967.

Foreign Relations of the United States - Diplomatic Papers (FRUS), 1945, volume IX, The American Republics. Washington: Government Printing Office, 1969. Foreign Relations of the United States - Diplomatic Papers (FRUS), 1950, volume I, National Security Affairs; Foreign Economic Policy. Washington: Government Printing Office, 1977.

GUILLOBEL, Renato de Almeida. Memórias. Rio de Janeiro: Fundação IBGE, 1973.

HILTON, Stanley. O Brasil e as Grandes Potências: os aspectos politicos da rivalidade comercial, 1930-1939. Rio de Janeiro: Civilização Brasileira, 1977.

Oswaldo Aranha - uma biografia. Rio de Janeiro: Objetiva, 1994.

HUMPHREYS, R. A.. Latin America and the Second World War, Volume Two 1942-1945. London: Athlone, 1982.

MARINHA ARGENTINA. Historia - La Armada del S.XX. Disponível em: $<$ http://www.ara.mil.ar>.

MARINHA DO BRASIL.

Relatório apresentado ao presidente da República pelo ministro de Estado da Marinha referente ao ano de 1946. Rio de Janeiro: Imprensa Naval, 1947. 
Relatório apresentado ao presidente da República pelo ministro de Estado da Marinha, referente ao periodo de outubro de 1946 a 1950. Rio de Janeiro: Imprensa Naval, 1951.

História Naval Brasileira, $5^{\circ}$ volume, tomo II. Rio de Janeiro: Serviço de Documentação Geral da Marinha, 1985.

História Naval Brasileira, $5^{\circ}$ volume, tomo I b. Rio de Janeiro: Serviço de Documentação da Marinha, 1997.

MCCANN, Frank D. Aliança Brasil-Estados Unidos, 1937/1945. Rio de Janeiro: Biblioteca do Exército, 1995.

MOREL, Edmar. A Revolta da Chibata.Rio de Janeiro: Edições Graal, 1986.

MOURA, Gerson. Autonomia na Dependência: A Política Externa Brasileira de 1935 a 1942. Rio de Janeiro: Nova Fronteira, 1980.

PACH JR., Chester J. "The Containment of U.S. Military Aid to Latin America, 1944-49” I Diplomatic History, vol. 6, n. o 3, 1982.

SCHEINA, Robert L. Latin America, a naval history 1810-1987. Annapolis: Naval Institute Press, 1987.

SILVEIRA, Cláudio C. A Marinha e a Política do Exército. In: Estudos de História - Franca, vol. 8, n. ${ }^{\circ}$ 1, 2001.

TELLES, Pedro Carlos da Silva. História da Construção Naval no Brasil. Rio de Janeiro: LAMN, FEMAR, 2001.

VIDIGAL, Armando Amorim Ferreira. A Evolução do Pensamento Estratégico Naval Brasileiro. Rio de Janeiro: Biblioteca do Exército, 1985.

\section{Resumo}

O americanismo foi a principal idéia norteadora da diplomacia brasileira na primeira metade do século XX. Os anos 40 constituíram o apogeu e o declínio desta idéia. A análise da política naval brasileira no período mostra o quanto ela foi influenciada pela aliança formal com os Estados Unidos dos tempos de guerra, e como se sonhou que a supremacia naval do Brasil no cone sul seria atingida com o auxílio norte-americano. $O$ fracasso desta política, entretanto, foi explicitado logo no início dos anos 50. A idéia da aliança especial contaminou todos os elementos inerentes ao poder nacional, e o caso da Marinha do Brasil serve para referendar este achado. 


\section{Abstract}

The Americanism was the main idea guiding Brazilian diplomacy in the twentieth century. The forties were the idea apogee and decline. The Brazilian naval policy analysis shows how much it was influenced by the war's formal alliance with the United States, and how they dreamed with Brazil's naval supremacy in the southern cone with American help. The failure of this policy came in the very beginning of the fifties. The special alliance idea ingrained in every aspect of the national power, and the Brazilian's navy case is showed to support this statement.

Palavras-chave: política externa brasileira, relações militares Brasil-Estados Unidos, política naval brasileira

Key words: Brazilian Foreign policy, Brazilian naval policy, Brazil-United States military relations 